\title{
Developmental toxicity and thyroid hormone-disrupting effects of 2,4-dichloro-6-nitrophenol in Chinese rare minnow (Gobiocypris
}

\section{rarus)}

\author{
Rui Chen, Lilai Yuan, Jinmiao Zha*, Zijian Wang \\ State Key Laboratory of Environmental Aquatic Chemistry, Research Center for Eco-Environmental Sciences, Chinese Academy of Sciences, P. O. Box 2871, \\ Beijing 100085, PR China
}

\section{A R T I C L E I N F O}

\section{Article history:}

Received 30 August 2016

Received in revised form 26 January 2017

Accepted 3 February 2017

Available online 4 February 2017

\section{Keywords:}

Chinese rare minnow

2,4-Dichloro-6-nitrophenol

Thyroid hormones

Hypothalamic-pituitary-thyroid axis

Endocrine disruption

\begin{abstract}
A B S T R A C T
In the present study, to evaluate embryonic toxicity and the thyroid-disrupting effects of 2,4-dichloro-6nitrophenol (DCNP), embryos and adults of Chinese rare minnow (Gobiocypris rarus) were exposed to 2 , 20 , and $200 \mu \mathrm{g} / \mathrm{L}$ DCNP. In the embryo-larval assay, increased percentages of mortality and occurrence of malformations, decreased percentage of hatching, and decreased body length and body weight were observed after DCNP treatment. Moreover, the whole-body T3 levels were significantly increased at 20 and $200 \mu \mathrm{g} / \mathrm{L}$ treatments, whereas the T4 levels were markedly decreased significantly $(\mathrm{p}<0.05)$ for all DCNP concentrations. In the adult fish assay, plasma T3 levels were significantly increased whereas plasma T4 levels were significantly reduced in the fish treated with 20 and $200 \mu \mathrm{g} / \mathrm{L}(\mathrm{p}<0.05)$. In addition, DCNP exposure significantly changed the transcription levels of thyroid system related genes, including dio1, dio2, me, nis, $t r$, and ttr. The increased responsiveness of thyroid hormone and mRNA expression levels of thyroid system related genes suggested that DCNP could disrupt the thyroid hormone synthesis and transport pathways. Therefore, our findings provide new insights of DCNP as a thyroid hormonedisrupting chemical.
\end{abstract}

(c) 2017 Elsevier B.V. All rights reserved.

\section{Introduction}

The thyroid hormone system plays a crucial role in the development, somatic growth, metabolism, energy provision, and reproduction of vertebrates (Schnitzler et al., 2012). During the early life stages of fish, thyroid hormones (THs) are essential for larval to juvenile metamorphosis (Blanton and Specker, 2007;

Abbreviations: 2,4-D, 2,4-dichlorophenoxyacetic acid; DCNP, 2,4-dichloro-6nitrophenol; DCP, 2,4-dichlorophenol; Dio, deiodinase; Dpf, days post-fertilization; EDCs, endocrine-disrupting chemicals; ELISA, enzyme-linked immunosorbent assay; GC-MS, gas chromatography/mass spectrometry; Hpf, hours postfertilization; HPT axis, hypothalamus-pituitary-thyroid axis; LOQ limit of quantification; Me, malic dehydrogenase; NIS, sodium-iodide symporter; PBDEs, polybrominated diphenyl ethers; PCP, pentachlorophenol; S.E.M., standard error of the mean; T3, 3,5,3'-triiodothyronine; T4, thyroxine; THDCs, thyroid hormone-disrupting chemicals; THs, thyroid hormones; TPO, thyroperoxidase; TR, thyroid hormone receptor; TRHR, thyrotropin-releasing hormone receptor; TTR, transthyretin.

* Corresponding author at: State Key Laboratory of Environmental Aquatic Chemistry, Research Center for Eco-Environmental Sciences, Shuangqing Rd 18, Haidian District, Beijing 100085, PR China.

E-mail address: jmzha@rcees.ac.cn (J. Zha).
Porazzi et al., 2009). Exogenous THs were found to accelerate zebrafish development, growth, and differentiation (Brown, 1997). Conversely, exposure to thyroid hormone-disrupting chemicals (THDCs) inhibited the larval metamorphosis (Crofton, 2008; Miller et al., 2009). However, in the embryos, the relationship between THs and embryonic development is not well documented (Blanton and Specker, 2007). The THs may play an important role during embryonic development since high concentrations of maternal THs have been detected in the embryos (Leatherland et al., 1989). Moreover, dio2 knock-down in zebrafish embryos induced developmental retardation (Walpita et al., 2009). Given the key role of THs in fish development, it is important to identify which THDCs adversely affect thyroid function.

Exposure to THDCs, including polychlorinated biphenyls, dioxins, phthalates, polybrominated diphenyl ethers (PBDEs), and other halogenated organochlorines, has been shown to interfere with the production, transport, and metabolism of THs (Patrick, 2009). In addition, substituted phenols (which have structural similarity to THs) were also considered to be THDCs. Numerous substituted phenols, including 2,4-dichlorophenol (Ghisari and Bonefeld-Jorgensen, 2009), pentachlorophenol (Dallaire et al., 2009; Kawaguchi et al., 2008; Sugiyama et al., 2005), 4-n- 
nonylphenol (Duffy et al., 2014), and 4-tert-octylphenol (Croteau et al., 2009), have the potential to disrupt thyroid endocrine activities at several different pre-receptor points of action (Guo and Zhou, 2013). Substituted phenols released into the environment can disrupt the hypothalamus-pituitary-thyroid (HPT) axis by interfering with TH synthesis, cellular uptake and metabolism due to their structural similarity to THs (Boas et al., 2012). Moreover, there is increasing evidence that thyroid hormone receptors (TRs) and transthyretins (TTRs) may be the targets of some substituted phenols (Carr and Patiño, 2011). Recently, pentachlorophenol (Guo and Zhou, 2013) and BPA (Gentilcore et al., 2013) were found to disrupt thyroid functions by binding to TR and TTR, altering HPT axisrelated gene expression. However, the thyroid hormone-disrupting effects of DCNP, a substituted phenol and an organochlorine chemical, are not well documented.

2,4-Dichloro-6-nitrophenol (DCNP) is an environmental transformation product of the ubiquitous 2,4-dichlorophenol (DCP) (Vione et al., 2006). Although DCNP is a rarely produced and used chemical, DCP is a key intermediate in the synthesis of chloridebased herbicides; both of these compounds have been detected in the surface water (Chen et al., 2016). DCNP has been detected in the brackish lagoons of southern France at a concentration of $1.32 \mu \mathrm{g} / \mathrm{L}$, which is comparable to the concentration of the parent herbicide $(4.72 \mu \mathrm{g} / \mathrm{L})$ (Chiron et al., 2007). The photonitration model to produce DCNP has been reported in previous studies: nitrite and nitrate ions may generate reactive species with sunlight and then attack the aromatic ring in the DCP. (Calza et al., 2008; Maddigapu et al., 2010; Vione et al., 2006, 2007). However, there is a lack of data about the toxicity and thyroid hormone disruption activity of DCNP in fish (Tognazzi et al., 2012).

Therefore, in the present study, to further clarify embryo toxicity and thyroid hormone disruption bu DCNP in fish, embryos of and adult rare minnows were exposed to an environmental concentration $(2 \mu \mathrm{g} / \mathrm{L})$ and two higher concentrations (20 and $200 \mu \mathrm{g} / \mathrm{L}$ ) of DCNP. The progression of early development, thyroid hormone levels and the mRNA expression levels of thyroid system-related genes were determined. Chinese rare minnow (Gobiocypris rarus) has the characteristics of a small size, short life cycle and prolific egg production, all of which contribute to the increase of the sample number, reduction of the deviation and shortening of the required experimental period (Yuan et al., 2016). The advantages of the optical clarity during embryogenesis and the early larval stages facilitate visual in vivo observation of early developmental processes (Zhu et al., 2014). From fertilization to hatching, the embryonic developmental period of Chinese rare minnow lasts for $72 \mathrm{~h}$ at $26^{\circ} \mathrm{C}$. The duration of postembryonic developmental period is 30 days, during which time Chinese rare minnows grow uniformly with a growth rate of $0.52 \mathrm{~mm}$ per day. Four months after hatch, Chinese rare minnow could attain sexual maturity (Liang and Zha, 2016). In previous studies, Chinese rare minnows were used as a model to evaluate the endocrine disruption effects of environmental pollutants such as 3-amino-1,2,4-triazole (Li et al., 2009) and benzotriazole (Liang et al., 2014).

\section{Materials and methods}

\subsection{Chemicals}

DCNP (CAS no. 609-89-2; purity >98\%) was purchased from Sigma-Aldrich (Chemical Co., Missouri, USA). A stock solution of DCNP was prepared by dilution in acetone (purity $>99.9 \%$; Sinopharm, China). All the resultant exposure media contained $0.01 \%$ acetone.

\subsection{Test fish and culture conditions}

The brood stock of Chinese rare minnows has been used by our laboratory to test chemicals for more than 14 years. The brood stock of Chinese rare minnow was raised in dechlorinated tap water $\left(25^{\circ} \mathrm{C}\right)$ using a flow-through system under a photoperiod of $16: 8 \mathrm{~h}$ (light:dark). Fish were fed a commercial food pellet (Trea, Germany) and newly hatched brine shrimp (Artemia nauplii) twice a day. All experimental procedures involving Chinese rare minnows were conducted in accordance with the Guide for the Care and Use of Laboratory Animals of China.

\subsection{Measured concentrations of DCNP}

The measured concentrations of DCNP were consistent over the renewal interval $(24 \mathrm{~h})$. Quantification of DCNP was conducted by gas chromatography/mass spectrometry (GC-MS). The test solutions were analyzed using the selected ion monitoring (SIM) mode and the retention time locking (RTL) method. For the recovery test, the selected optimized elution solvents of DCNP were used. According to the experimental results, the matrix spike recovery for DCNP is $74.56 \%$. The instrument limit of quantification (LOQs) of DCNP is $10 \mathrm{pg}$. The analyzed concentrations (mean \pm standard deviation; \% analyzed/nominal) of DCNP in the test solutions during the exposure period were $1.68 \pm 0.39$ (84\%), $16.3 \pm 2.63$ (82.5\%), $158 \pm 21.2$ (79\%) $\mu \mathrm{g} / \mathrm{L}$. For simplicity, nominal concentrations are used when presenting the results in this paper.

\subsection{Embryos exposure to DCNP}

Fertilized eggs were examined under a dissecting microscope, and those that had reached the blastula stage ( $2 \mathrm{~h}$ post-fertilization, hpf) were selected for experiments. Approximately 1440 embryos were randomly distributed into aseptic 24-well plates containing $1 \mathrm{ml}$ of DCNP solution $(0,2,20$, or $200 \mu \mathrm{g} / \mathrm{L}$ ). Forty wells (three healthy embryos per well) were treated as one group, and there were three groups for each treatment. During the experimental period, the exposure solution was replaced daily, and rare minnow larvae were fed cultured live brine shrimp twice daily. When yolk-sac had nearly disappeared, the rare minnow larvae were first fed at $48 \mathrm{~h}$ after hatch. The embryos were observed for 120 continuous hours to determine the percentage of mortality, hatching and occurrence of malformations. Lethal effects, including yolk coagulation and gastrula inactivation, and the malformation types, including yolk sac edema, pericardial edema, axial curvature, uninflated swim bladder and caudal fin malformation, were recorded daily. At 14 days post-fertilization (dpf), the larvae were randomly sampled, immediately frozen in liquid nitrogen, and stored at $-80^{\circ} \mathrm{C}$ for subsequent analysis of gene transcription and THs.

\subsection{Adult fish exposure to DCNP}

Healthy adult rare minnows (seven months old) from the same pair of brood stock were used in this experiment. These adult rare minnows were kept in 16-L glass aquaria and exposed to various concentrations $(0,2,20$, and $200 \mu \mathrm{g} / \mathrm{L})$ of DCNP. Experiments were carried out in triplicate for each exposure concentration and each glass aquarium contained 30 adult rare minnows. The exposure solutions were completely replaced once per day. Fish were fed twice a day with newly hatched brine shrimp. After 14 and 28 days of exposure, the fish were removed from experimental tanks, anesthetized with MS-222, and immediately sacrificed following the recording of the fishes' length and weight. The tissues were excised, immediately frozen in liquid nitrogen and stored at $-80^{\circ} \mathrm{C}$. 


\subsection{Thyroid hormone assays}

In the embryo experiment, a subset of the 15-dpf larvae from each replicate was sampled at random to measure thyroid hormone levels. Ten larvae were homogenized and stored overnight at $-20^{\circ} \mathrm{C}$ with PBS as one replicate. There were six replicates for each treatment and control. After two freeze-thaw cycles and centrifugation $(3000 \times g, 10 \mathrm{~min})$, the supernatants were removed. All of the extracts were resuspended and assayed immediately. In the adult experiment, all fish were anesthetized on ice after the 28 day of exposure, and plasma was collected using heparin as an anticoagulant. After centrifugation within $30 \mathrm{~min}$ of blood collection, plasma was collected and assayed immediately. The plasma samples from ten Chinese rare minnows were pooled as one replicate. There were six replicates for each treatment and control. The total concentrations of T3 and T4 were measured in triplicate using commercial enzyme-linked immunosorbent assay (ELISA) kits (Uscn Life Science Inc., Wuhan, China) according to the manufacturer's instructions. The detection range reported by the manufacturer was $0.5 \mathrm{ng} / \mathrm{ml}-8 \mathrm{ng} / \mathrm{ml}$ for T3 and $40 \mathrm{ng} / \mathrm{ml}-300 \mathrm{ng} / \mathrm{ml}$ for T4, and the intra- and inter-assay coefficients of variation were $<10 \%$.

\subsection{Determining gene expression by real-time PCR}

Total RNA was extracted from either whole animals ( $\mathrm{n}=3$ replicates per treatment, 15 larvae per replicate) or dissected organs $(\mathrm{n}=3$ replicates per treatment, 6 adult fish per replicate) using SV Total RNA Isolation kits (Promega, Madison, WI, USA). RNA was treated with DNAse and reverse transcribed with RQ1 and M-MLV Reverse Transcriptase (Promega, Madison, WI, USA). The forward/reverse primers are listed in Table S1. Briefly, real-time PCR was performed using the 7500 Fast Real-Time PCR system (Life Technologies, USA) and the Brilliant II SYBR Green QPCR master mix. The cycling parameters were as follows: $95^{\circ} \mathrm{C}$ for $8 \mathrm{~min}$ and 40 cycles of $95^{\circ} \mathrm{C}$ for $15 \mathrm{~s}, 57^{\circ} \mathrm{C}$ for $30 \mathrm{~s}$ and $72^{\circ} \mathrm{C}$ for $30 \mathrm{~s}$. For each sample, a melting curve analysis was performed on the PCR products at the end of each run to ensure that a single product was amplified. To determine the efficiency of the PCR reaction, standard curves and primer efficiencies were determined for target genes and the endogenous control gene $\beta$-actin with 10 serial dilutions of the cDNA samples. The PCR efficiencies ranged from $89.1 \%$ to $97.0 \%$ in the present study. The basal mRNA expression for the selected genes was calculated by the $2^{-\Delta \Delta \mathrm{Ct}}$ method using $\beta$-actin as the reference gene. The ratios for the treated samples were calculated by comparing the expression values to those in the control group. Nine genes related to thyroid system have been determined: dio1 (deiodinase type 1), dio2, dio3, me (malic dehydrogenase), nis (sodium-iodide symporter), tpo (thyroperoxidase), tr (thyroid hormone receptor), trhr (thyrotropin-releasing hormone receptor) and ttr (transthyretin).

\subsection{Statistical analysis}

The experimental data were checked for normality and homogeneity of variance using Kolmogorov-Smirnov and Levene's tests, respectively. All of the results were expressed as the mean \pm standard error of the mean (S.E.M.). The means of each replicate for exposure and control groups were analyzed by oneway analysis of variance (ANOVA) followed by Dunnett's multiple comparisons test using SPSS 13.0 (SPSS, Chicago, IL, USA) and OriginPro 8.0 (OriginLab, Northampton, MA, USA). Statistical significance was considered when the p-values were less than 0.05 .

\section{Results}

\subsection{Embryonic toxicity of DCNP}

\subsubsection{Hatching, mortality and malformations}

The cumulative hatching percentages of embryos exposed to DCNP are shown in Fig. 1a and Table S2. Compared with the control group, there were no significant differences in the hatching percentages of embryos following exposure to either 2 or $20 \mu \mathrm{g} / \mathrm{L}$ DCNP. However, the percentage of hatching was significantly decreased by the highest concentration $(200 \mu \mathrm{g} / \mathrm{L})$ of DCNP after 72 hpf. Compared to the control fish, obvious mortality changes were observed between the control groups and the $200 \mu \mathrm{g} / \mathrm{L}$ groups (Fig. 1b, Table 2 and Table S3). Typical malformations of embryos exposed to DNCP were detected and are shown in Fig. 2 and Table 1. In the present study, the observed typical malformations included spinal scoliosis, yolk sac edema, pericardial edema and an uninflated swim bladder.

In the embryo experiment, the body length and body weight were significantly decreased in the $200 \mu \mathrm{g} / \mathrm{L}$ treatment group $(\mathrm{p}<0.05)$, whereas no significant change in the 2 and $20 \mu \mathrm{g} / \mathrm{L}$ treatment groups was observed (Table 2 ).

\subsubsection{Thyroid hormone levels in exposed embryos}

A significant decreasing trend of whole-body $\mathrm{T} 4$ expression was observed in all of the treatment groups after $14 \mathrm{~d}$ of exposure ( $\mathrm{p}<0.05$; Fig. 3). Moreover, exposure of embryos to $20 \mu \mathrm{g} / \mathrm{L}$ DCNP resulted in a significant increase in whole-body T3 level, but this
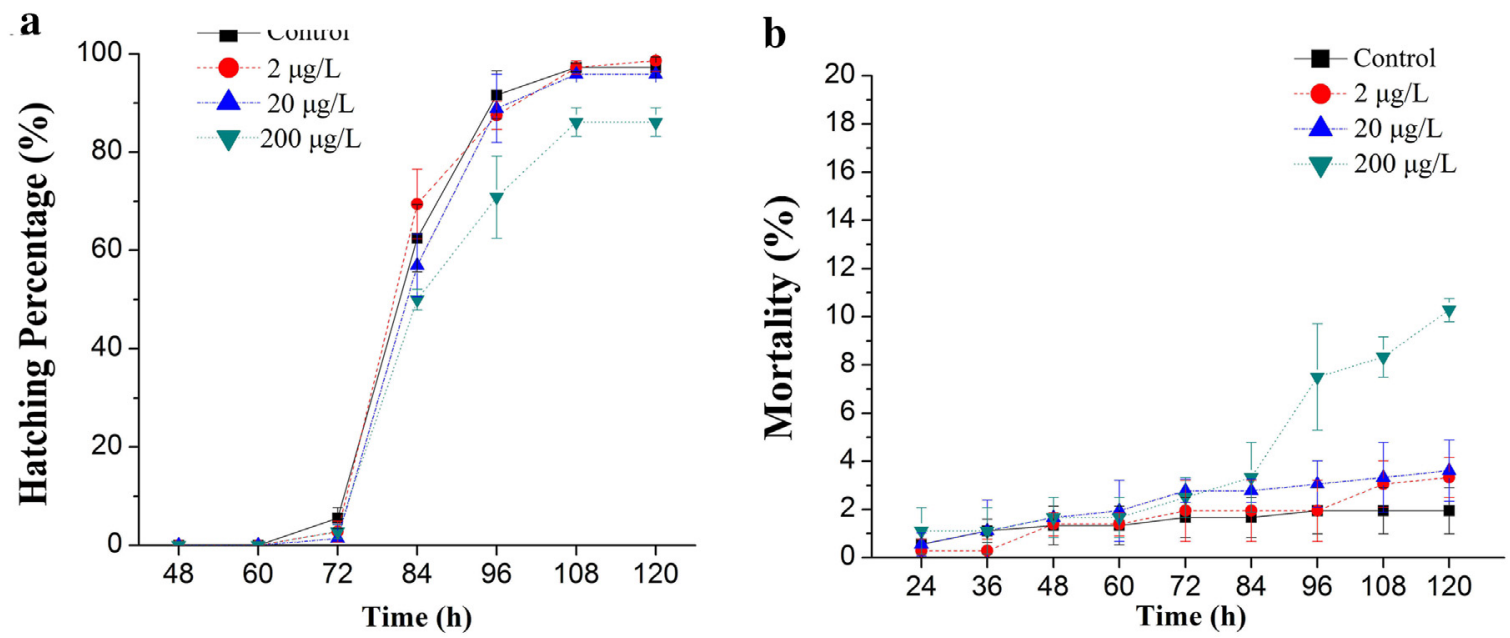

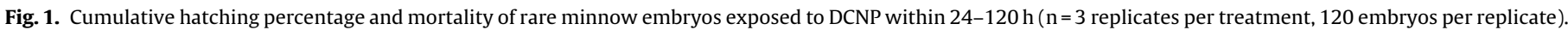




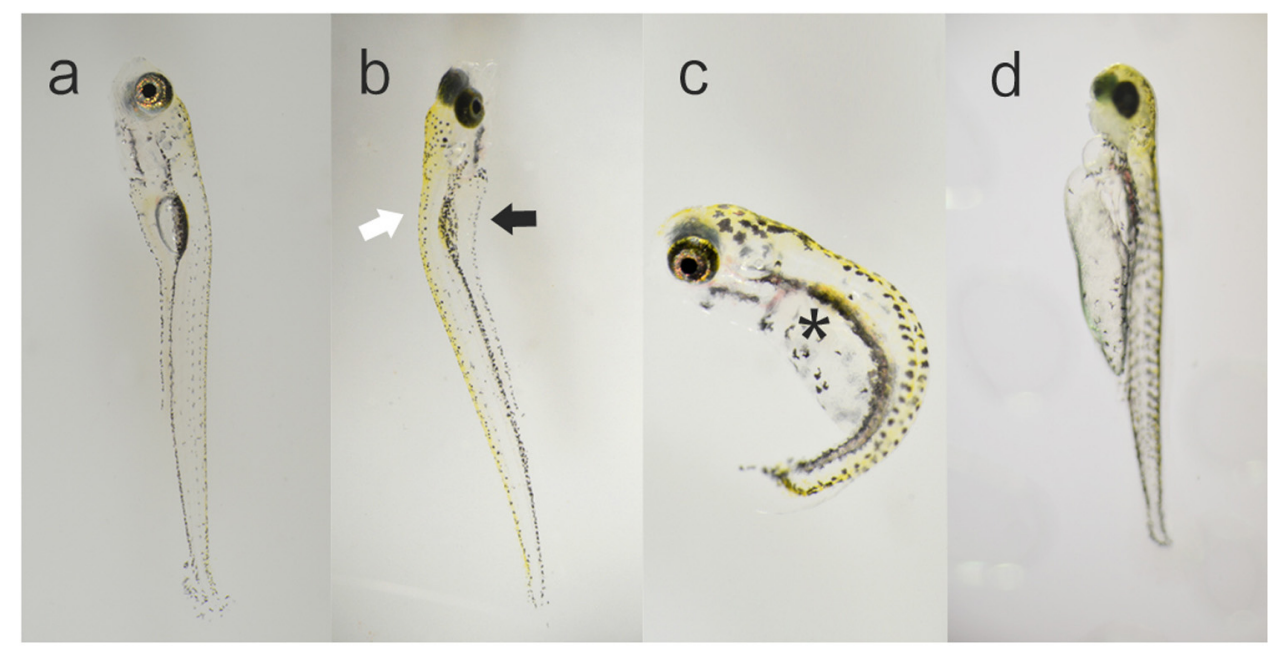

Fig. 2. Lesion occurrence in DCNP exposure embryos/larvae. (a) Normal rare minnow. (b) an undeveloped, uninflated swim bladder (black arrow) and spinal scoliosis (white arrow). (c) yolk sac and pericardial edema (black asterisk). (d) pericardial edema.

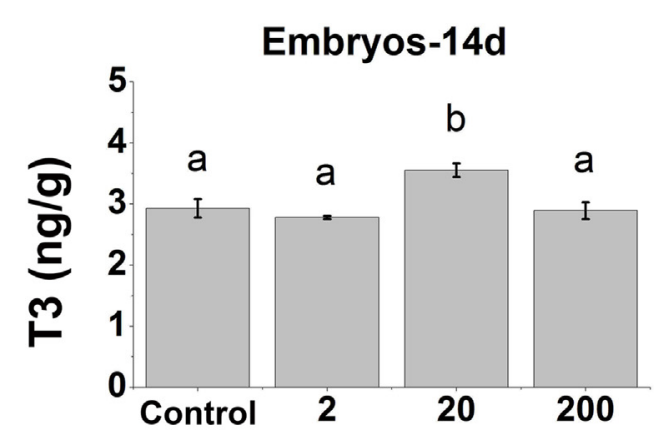

Adult-14d

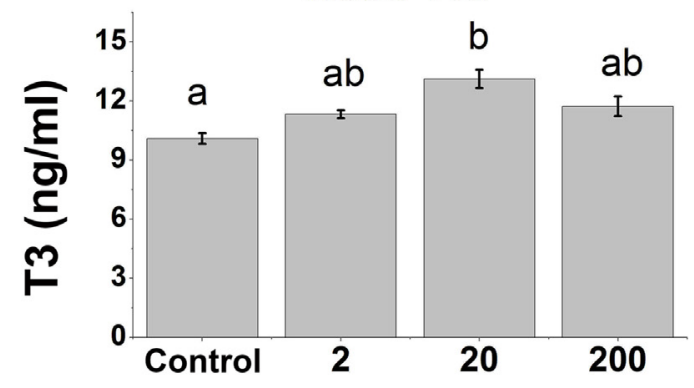

Adult-28d

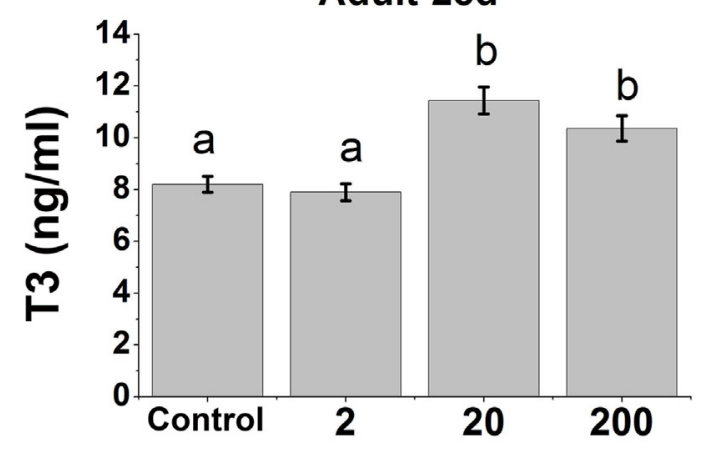

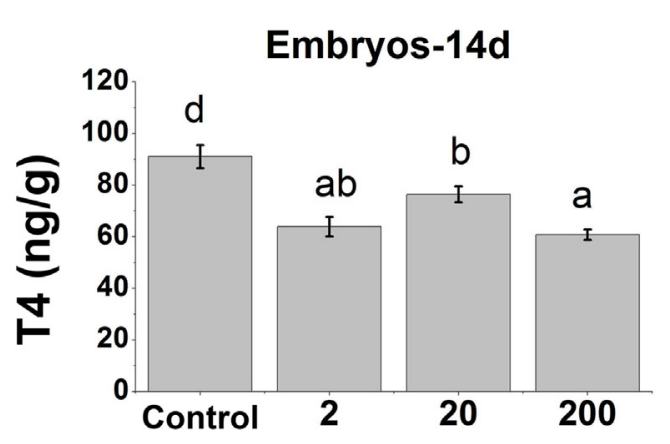

Adult-14d
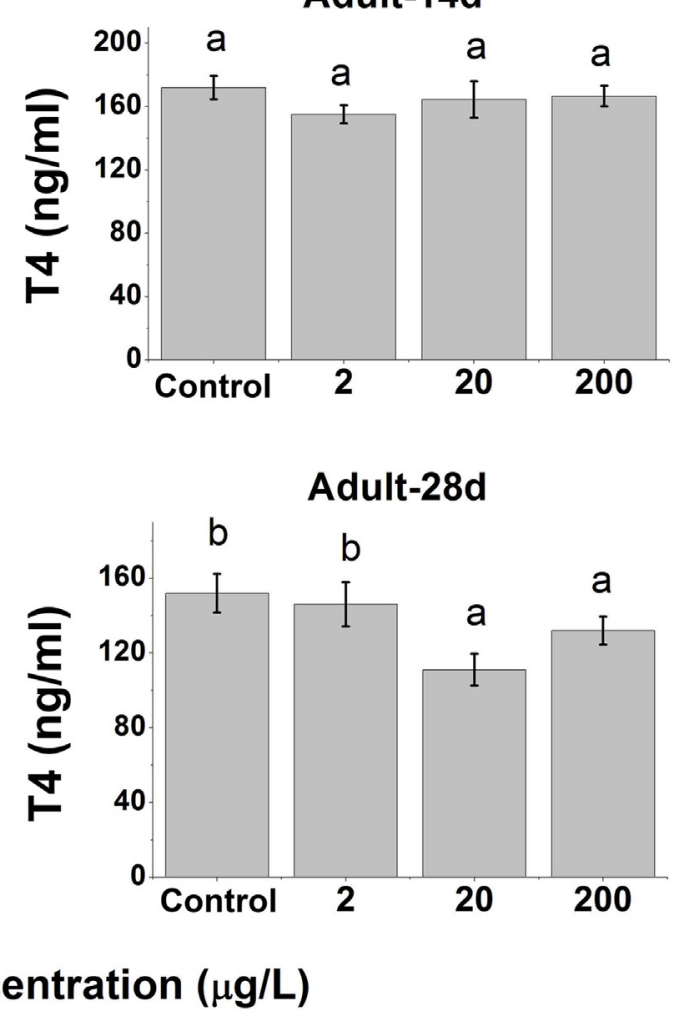

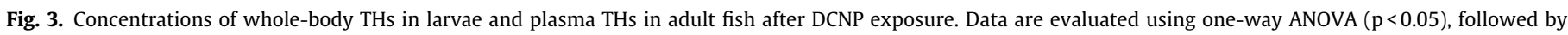
Dunnett's test for multiple comparisons. Results are expressed as mean \pm SEM of six replicate samples. 
Table 1

Malformation percentage (\%) observed in larvae of rare minnow exposed to DCNP.

DCNP Concentration $(\mu \mathrm{g} / \mathrm{L})$

0

\begin{tabular}{|c|c|}
\hline Spinal scoliosis & $1.39 \pm 0.96 \%$ \\
\hline Yolk sac edema & $0.00 \%$ \\
\hline Pericardial edema & $0.00 \%$ \\
\hline Uninflated swim bladder & $0.28 \pm 0.48 \%$ \\
\hline
\end{tabular}

Table 2

Body length, body weight and cumulative mortality of larva on $14 \mathrm{dpf}$.

\begin{tabular}{llll}
\hline & Body length & Body weight & Cumulative mortality \\
\hline Control & $6.93 \pm 0.23$ & $2.52 \pm 0.22$ & $2.64 \pm 0.97 \%$ \\
$2 \mu \mathrm{g} / \mathrm{L}$ & $6.78 \pm 0.50$ & $2.54 \pm 0.51$ & $3.47 \pm 1.11 \%$ \\
$20 \mu \mathrm{g} / \mathrm{L}$ & $6.76 \pm 0.27$ & $2.35 \pm 0.36$ & $4.72 \pm 1.72 \%$ \\
$200 \mu \mathrm{g} / \mathrm{L}$ & $6.06 \pm 0.32^{*}$ & $1.84 \pm 0.33^{*}$ & $19.72 \pm 4.21 \%$ \\
\hline
\end{tabular}

Data expressed as mean \pm S.E. of each treatment.

Three replicates per treatment (120 embryos per replicate)

* Statistically significant difference from the control $(\mathrm{p}<0.05)$.
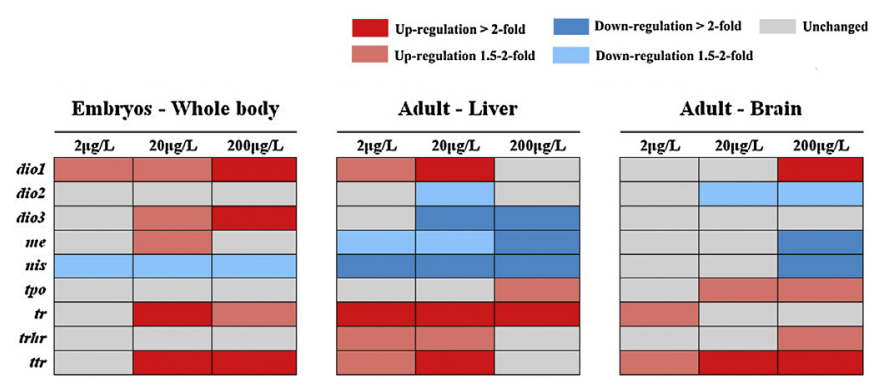

Fig.4. Transcript expressions of the selected transcriptiome of Chinese rare minnow in response to different concentrations of DCNP exposure. In the embryo experiment, genes related to the thyroid system (dio1, dio2, dio3, me, nis, tpo, tr, trhr and ttr) were investigated at $14 \mathrm{dpf}$ ( $\mathrm{n}=3$ replicates per treatment, 15 larvae per replicate). In the adult fish experiment, the transcription levels of 9 genes were investigated in the liver and brain after $28 \mathrm{~d}$ exposure of DCNP ( $n=3$ replicates per treatment, 6 adult fish per replicate). Expression profiles were represented by heat map.

was not statistically significant between the other treatments and controls (Fig. 3).

\subsubsection{Gene transcription in the thyroid system}

Genes related to thyroid system (dio1, dio2, dio3, me, nis, tpo, tr, trhr and ttr) were investigated (Supplemental Table S1 and Fig. 4) at $14 \mathrm{dpf}$. The transcriptional levels of dio1 and dio3 were significantly increased in the $200 \mu \mathrm{g} / \mathrm{L}$ treatment group ( $\mathrm{p}<0.05$ ), whereas no significant changes in me, nis, tpo, and trhr were observed. Both $t r$ and $t$ tr were significantly up-regulated in the 20 and $200 \mu \mathrm{g} / \mathrm{L}$ treatment groups $(\mathrm{p}<0.05)$.

\subsection{Thyroid hormone-disrupting effects in exposed adult fish}

\subsubsection{Mortality and growth of adult fish}

No mortality was observed. The body length, body weight, HSI and GSI of the rare minnows in none of the treatment groups showed statistically significant differences compared to the control group (data not shown).

\subsubsection{Plasma thyroid hormone levels}

After $14 \mathrm{~d}$ of exposure, only the plasma T3 concentration in the $20 \mu \mathrm{g} / \mathrm{L}$ group was significantly higher than in the control group $(\mathrm{p}<0.05$; Fig. 3). A comparison of the concentration of plasma T4 between the control and exposure groups failed to reveal any significant change after $14 \mathrm{~d}$ of exposure. After $28 \mathrm{~d}$ of exposure, the plasma T3 concentration was significantly increased in the 20 and $200 \mu \mathrm{g} / \mathrm{L}$ DCNP treatment groups ( $<<0.05$; Fig. 3) whereas the plasma T4 levels were significantly decreased in the 20 and $200 \mu \mathrm{g} / \mathrm{L}$ DCNP treatment groups ( $\mathrm{p}<0.05$; Fig. 3).

\subsubsection{Gene transcription in the thyroid system}

In the adult fish experiment, the transcription levels of 9 genes related to the thyroid system were investigated in the liver after 28 d exposure (Supplemental Table S2 and Fig. 3). The transcriptional levels of me and nis were decreased in all of the exposure groups, whereas $\operatorname{tr}$ was significantly up-regulated $(\mathrm{p}<0.05)$. In addition, the levels of dio1 and ttr were increased in the group treated with $20 \mu \mathrm{g} / \mathrm{L}$ DCNP, whereas dio3 was decreased upon treatment with 20 and $200 \mu \mathrm{g} / \mathrm{L}$ DCNP. No significant changes in dio2, tpo, and trhr were observed.

In the brain, the level of dio1 was significantly increased in the $200 \mu \mathrm{g} / \mathrm{L}$ group, whereas me and nis were significantly downregulated in this group (Supplemental Table S3 and Fig. 3). The mRNA expression levels of $t$ tr were significantly up-regulated upon treatment with 20 and $200 \mu \mathrm{g} / \mathrm{L}$ DCNP in a concentrationdependent manner. Meanwhile, no significant differences were observed in the transcriptional levels of dio2, dio3, tpo, tr and trhr in the brain.

\section{Discussion}

As an environmental transformation product of DCP, DCNP may leak into the environment and possibly disrupt endocrine systems. In the present study, the increased percentages of mortality and occurrence of malformations as well as the decreased percentage of hatching were found in the Chinese rare minnow embryo upon exposure to DCNP, indicating a potential developmental toxicity. The thyroid hormone assays showed that $\mathrm{T} 3$ levels increased whereas T4 levels decreased in the embryos and adult rare minnows upon DCNP exposure. Substituted phenols may have a direct impact on TH levels by interfering with the thyroid metabolism, transport and clearance (Jugan et al., 2010). Thus, we investigated the expression changes in thyroid system related genes after exposure to DCNP. It should be noted that expressions of ttr and dio1 occur mainly in the hepatocytes, while dio2 and dio3 are distributed in the brain. In the thyroid follicular cells, tpo and nis are used to control iodide uptake and TH synthesis (Raldua et al., 2012). In this experiment, significant changes in dio, ttr and $t r$ were observed in larvae and liver of fish. These results clearly demonstrated that DCNP can directly interact with thyroid system in Chinese rare minnows.

The significant increase in embryonic mortality and occurrence of malformations following exposure to $200 \mu \mathrm{g} / \mathrm{L}$ DCNP indicated that DCNP could cause embryonic toxicity. In previous studies, there was only one case reporting the $\mathrm{LC}_{50}$ value of DCNP (18.7 $\pm 0.8 \mathrm{mg} / \mathrm{L}$, Artemia salina, 1 day) (Tognazzi et al., 2012). More- 
over, a variety of malformations in the embryos of rare minnows such as spinal scoliosis, uninflated swim bladder, and yolk sac and pericardial edema were observed after DCNP exposure. The swim bladder is required for fish to maintain a vertical position in water, which is crucial for survival in most fish species (Yue et al., 2015). Aside from DCNP, exposure to dioxin (Yue et al., 2015), PCBs (Jönsson et al., 2012) and chitosan (Wang et al., 2016) also resulted in an uninflated swim bladder. Thus, our findings demonstrate that exposure to DCNP results in a reduction in embryonic survival and hatching percentage as well as an increase in the occurrence of a variety of developmental lesions.

In the embryo experiment, T3 levels were increased following exposure to $20 \mu \mathrm{g} / \mathrm{L}$ DCNP whereas T4 levels were decreased in all exposure groups after $14 \mathrm{~d}$ of exposure. In previous studies, either 2,4-dichlorophenoxyacetic acid (2,4-D) or 4-nonylphenol induced the decreased T4 in newly hatched zebrafish (Raldúa and Babin, 2009). THs are critical for growth and development. It is clear that severe developmental hypothyroidism is profoundly detrimental to early development. Some studies evaluated both the developmental toxicity and thyroid-disruptive effects of endocrine-disrupting chemicals (EDCs), such as T3 (Walpita et al., 2007), perfluorooctane sulfonate (PFOS) (Shi et al., 2008), tetrabromobisphenol A (TBBPA) (Jagnytsch et al., 2006), tris(1,3dichloroisopropyl)phosphate (TDCPP) (Wang et al., 2013) and polybrominated diphenyl ethers (PBDEs) (Yu et al., 2010). However, during the early life stages, the thyroid is fully differentiated at approximately $55 \mathrm{~h}$ post fertilization (hpf) (Alt et al., 2006; Porazzi et al., 2009). Although concentrations of THs in fish eggs are measurable, the role of THs in developing embryos and the absolute requirements of THs are not well known (Blanton and Specker, 2007). Our results show that there may be a relationship between developmental toxicity and the concentrations of thyroid hormone. T3 is the most active hormone and binds with high affinity to nuclear receptors (TRs), whereas T4 is the precursor of T3, binds with low affinity and has few direct actions (Boas et al., 2012). In the adult fish experiment, T4 levels were decreased, whereas T3 levels were significantly elevated after adult rare minnows were exposed to DCNP for 28 days. Decreased T4 and increased T3 levels are frequently observed in fish exposed to TH endocrine disruptors, including PBDEs (Chen et al., 2012; Richardson et al., 2008; Szabo et al., 2008; Yu et al., 2010), PCP (Guo and Zhou, 2013), and PCBs (Martin and Klaassen, 2010; Schnitzler et al., 2011).

Three genes encoding deiodinase enzymees, dio1-dio3, are important for iodine metabolism and thyroid hormone degradation in livers (Jarque and Piña, 2014). In teleost fish, T3, which is derived from the localized metabolism of T4 by Dio1 and Dio2, is converted into inactive T2 by Dio3 (Fort et al., 2007). Three iodothyronine deiodinases, Dio1-Dio3, are believed to maintain hormone levels (Schnitzler et al., 2012) and the transcription of genes encoding them has been used as sensitive biomarker of thyroid disruption in fish. Dong et al. (2013) have reported that genes encoding deiodinases are expressed in the periventricular zone of the brain, the liver, thyroid follicles and the pronephric duct (Dong et al., 2013). In the present study, $20 \mu \mathrm{g} / \mathrm{L}$ DCNP treatments produced a significant induction of dio1 mRNA expression in the livers of fish, while the T3 levels increased following exposure to $20 \mu \mathrm{g} / \mathrm{L}$ DCNP, suggesting that the increased T3 levels could be related to the expression of dio1. Similar results were also obtained in zebrafish larvae exposed to TDCPP, pentachlorophenol, 6-OH-BDE-47 and 3-amino-1,2,4triazole; the study interpreted that modulating the expression of dio 1 could be a compensatory mechanism in response to increased plasma T3 levels (Li et al., 2009).

THDCs, especially BPA and PBDEs (Blanco et al., 2011), can bind to thyroid hormone receptor (TR) and might induce complex effects on thyroid hormone signaling (Yang et al., 2007). TR $\alpha$, which is encoded by the tro genes, plays crucial roles in embryogenesis and larval development (Liu et al., 2000; Zoeller and Tan, 2007). In the present study, tr $\alpha$ mRNA levels in the liver increased significantly whereas the mRNA levels in the brain remained unchanged after DCNP exposure. Differential expression of tr $\alpha$ implied that TR might be expressed in a tissue-specific manner. Previous studies have reported the up-regulation of tr $\alpha$ with T3 treatment (Crump et al., 2008; Freitas et al., 2011). Thus, abnormal tro expression was related to TH disruption and the increased levels of T3 (Matsubara K et al., 2012). Increased tr $\alpha$ expression also might result in the failure of THs to bind and activate the appropriate downstream response cascades (Shi et al., 2009).

Transthyretin (TTR) is a thyroid hormone-binding protein (THBP) in vertebrates and is the major TH carrier protein in fish (Marchesini et al., 2008). TTR activity in fish is sensitive to environmental contaminants and is a useful biomarker for thyroid disruption in fish (Marchesini et al., 2006; Richardson et al., 2008). Previous studies have reported that PCB-mediated decreases in serum T4 levels were dependent on the inhibition T4-TTR complex formation in serum (Kato et al., 2012). In the present study, ttr gene expression was up-regulated upon DCNP exposure, which might impact the transport and binding of THs and thus pose a potential risk to thyroid function. Up-regulated $t$ tr gene expression was also reported in sea bream exposed to PBDs and zebrafish exposed to pentachlorophenol (Morgado et al., 2007; Guo and Zhou, 2013). The enhanced ttr mRNA levels indicate that variations in ttr expression had contributed to the disruption of the thyroid endocrine system. Moreover, some EDCs that share structural similarity to THs may have the ability to strongly bind TTR and disrupt the homeostasis of TH levels (Marchesini et al., 2008, 2006). Previous studies have reported that pentachlorophenol, 4-nonylphenol and BDEs can efficiently bind to TTR and disrupt the HPT-axis (Morgado et al., 2007). In summary, our results suggest that DCNP-mediated thyroid system disruption occurs, at least in part, through the disruption of the TH transport system.

\section{Conclusion}

This study evaluated the toxicity of DCNP on the embryonic development and thyroid system of Chinese rare minnows. The increased mortality, decreased hatching percentage, various malformations and inhibited development of rare minnow embryos after DCNP treatment occurred in a concentration-dependent manner. In addition, DCNP exposure of Chinese rare minnows at different life stages influenced the levels of THs as well as gene transcription in the thyroid system. Our results demonstrated that DCNP had thyroid-disruptive effects in Chinese rare minnows and can therefore be considered as a thyroid hormone-disrupting chemical.

\section{Acknowledgements}

This work was supported by the Key Program of the National Natural Science Foundation of China (21437006), the Major International Joint Research Project of the National Natural Science Foundation of China (51420105012), and the Water Pollution Control and Treatment of the National Science and Technology Major Project (2014zX-07204-008-003).

\section{Appendix A. Supplementary data}

Supplementary data associated with this article can be found, in the online version, at http://dx.doi.org/10.1016/j.aquatox.2017.02. 005. 


\section{References}

Alt, B., Reibe, S., Feitosa, N.M., Elsalini, O.A., Wendl, T., Rohr, K.B., 2006. Analysis of origin and growth of the thyroid gland in zebrafish. Dev. Dyn. 235, 1872-1883.

Blanco, J., Mulero, M., Lopez, M., Domingo, J.L., Sanchez, D.J., 2011. BDE-99 deregulates BDNF, Bcl-2 and the mRNA expression of thyroid receptor isoforms in rat cerebellar granular neurons. Toxicology 290, 305-311.

Blanton, M.L., Specker, J.L., 2007. The hypothalamic-pituitary-thyroid (HPT) axis in fish and its role in fish development and reproduction. Crit. Rev. Toxicol. 37, 97-115.

Boas, M., Feldt-Rasmussen, U., Main, K.M., 2012. Thyroid effects of endocrine disrupting chemicals. Mol. Cell. Endocrinol. 355, 240-248.

Brown, D.D., 1997. The role of thyroid hormone in zebrafish and axolot development. Proc. Natl. Acad. Sci. 94, 13011-13016.

Calza, P., Massolino, C., Pelizzetti, E., Minero, C., 2008. Solar driven production of toxic halogenated and nitroaromatic compounds in natural seawater. Sci. Total Environ. 398, 196-202.

Carr, J.A., Patiño, R., 2011. The hypothalamus-pituitary-thyroid axis in teleosts and amphibians: endocrine disruption and its consequences to natural populations. Gen. Comp. Endocrinol. 170, 299-312.

Chen, Q., Yu, L., Yang, L., Zhou, B., 2012. Bioconcentration and metabolism of decabromodiphenyl ether (BDE-209) result in thyroid endocrine disruption in zebrafish larvae. Aquat. Toxicol. 110-111, 141-148.

Chen, R., Liu, C., Yuan, L., Zha, J., Wang, Z., 2016. 2, 4-Dichloro-6-nitrophenol, a photonitration product of 2, 4-dichlorophenol, caused anti-androgenic potency in Chinese rare minnows (Gobiocypris rarus). Environ. Pollut. 216, 591-598.

Chiron, S., Minero, C., Vione, D., 2007. Occurrence of 2, 4-dichlorophenol and of 2 4-dichloro-6-nitrophenol in the Rhône river delta (Southern France). Environ. Sci. Technol. 41, 3127-3133.

Crofton, K.M., 2008. Thyroid disrupting chemicals: mechanisms and mixtures. Int J. Androl. 31, 209-223.

Croteau, M.C., Davidson, M., Duarte-Guterman, P., Wade, M., Popesku, J.T., Wiens, S., Lean, D.R., Trudeau, V.L., 2009. Assessment of thyroid system disruption in Rana pipiens tadpoles chronically exposed to UVB radiation and 4-tert-octylphenol. Aquat. Toxicol. 95, 81-92.

Crump, D., Jagla, M.M., Chiu, S., Kennedy, S.W., 2008. Detection of PBDE effects on mRNA expression in chicken (Gallus domesticus) neuronal cells using real-time RT-PCR and a new differential display method. Toxicol. In Vitro 22, 1337-1343.

Dallaire, R., Muckle, G., Dewailly, É., Jacobson, S.W., Jacobson, J.L., Sandanger, T.M., Sandau, C.D., Ayotte, P., 2009. Thyroid hormone levels of pregnant Inuit women and their infants exposed to environmental contaminants. Environ. Health Perspect. 117, 1014-1020.

Dong, W., Macaulay, L.J., Kwok, K.W., Hinton, D.E., Stapleton, H.M., 2013. Using whole mount in situ hybridization to examine thyroid hormone deiodinase expression in embryonic and larval zebrafish: a tool for examining $\mathrm{OH}-\mathrm{BDE}$ toxicity to early life stages. Aquat. Toxicol. 132, 190-199.

Duffy, T.A., Iwanowicz, L.R., McCormick, S.D., 2014. Comparative responses to endocrine disrupting compounds in early life stages of Atlantic salmon, Salmo salar. Aquat. Toxicol. 152, 1-10.

Fort, D.J., Degitz, S., Tietge, J., Touart, L.W., 2007. The hypothalamic-pituitary-thyroid (HPT) axis in frogs and its role in frog development and reproduction. Crit. Rev. Toxicol. 37, 117-161.

Freitas, J., Cano, P., Craig-Veit, C., Goodson, M.L., Furlow, J.D., Murk, A.J., 2011. Detection of thyroid hormone receptor disruptors by a novel stable in vitro reporter gene assay. Toxicol. In Vitro 25, 257-266.

Gentilcore, D., Porreca, I., Rizzo, F., Ganbaatar, E., Carchia, E., Mallardo, M., De Felice, M., Ambrosino, C., 2013. Bisphenol A interferes with thyroid specific gene expression. Toxicology 304, 21-31.

Ghisari, M., Bonefeld-Jorgensen, E.C., 2009. Effects of plasticizers and their mixtures on estrogen receptor and thyroid hormone functions. Toxicol. Lett. 189, 67-77.

Guo, Y., Zhou, B., 2013. Thyroid endocrine system disruption by pentachlorophenol: an in vitro and in vivo assay. Aquat. Toxicol. 142-143, $138-145$.

Jönsson, M.E., Kubota, A., Timme-Laragy, A.R., Woodin, B., Stegeman, J.J., 2012. Ahr2-dependence of PCB126 effects on the swim bladder in relation to expression of CYP1 and cox-2 genes in developing zebrafish. Toxicol. Appl. Pharmacol. 265, 166-174.

Jagnytsch, O., Opitz, R., Lutz, I., Kloas, W., 2006. Effects of tetrabromobisphenol A on larval development and thyroid hormone-regulated biomarkers of the amphibian Xenopus laevis. Environ. Res. 101, 340-348.

Jarque, S., Piña, B., 2014. Deiodinases and thyroid metabolism disruption in teleost fish. Environ. Res. 135, 361-375.

Jugan, M.L., Levi, Y., Blondeau, J.P., 2010. Endocrine disruptors and thyroid hormone physiology. Biochem. Pharmacol. 79, 939-947.

Kato, Y., Tamaki, S., Haraguchi, K., Ikushiro, S., Sekimoto, M., Ohta, C., Endo, T., Koga, N., Yamada, S., Degawa, M., 2012. Comparative study on 2,2',4,5,5'-pentachlorobiphenyl-mediated decrease in serum thyroxine level between C57BL/6 and its transthyretin-deficient mice. Toxicol. Appl. Pharmacol. 263, 323-329.

Kawaguchi, M., Morohoshi, K., Saita, E., Yanagisawa, R., Watanabe, G., Takano, H., Morita, M., Imai, H., Taya, K., Himi, T., 2008. Developmental exposure to pentachlorophenol affects the expression of thyroid hormone receptor ( 1 and synapsin I in brain, resulting in thyroid function vulnerability in rats. Endocrine 33, 277-284.
Leatherland, J., Lin, L., Down, N., Donaldson, E., 1989. Thyroid hormone content of eggs and early developmental stages of five Oncorhynchus species. Can. J. Fish. Aquat. Sci. 46, 2140-2145.

Li, W., Zha, J., Spear, P.A., Li, Z., Yang, L., Wang, Z., 2009. Changes of thyroid hormone levels and related gene expression in Chinese rare minnow (Gobiocypris rarus) during 3-amino-1, 2, 4-triazole exposure and recovery. Aquat. Toxicol. 92, 50-57.

Liang, X., Zha, J., 2016. Toxicogenomic applications of Chinese rare minnow (Gobiocypris rarus) in aquatic toxicology. Comp. Biochem. Physiol. D 19, $174-180$.

Liang, X., Wang, M., Chen, X., Zha, J., Chen, H., Zhu, L., Wang, Z., 2014. Endocrine disrupting effects of benzotriazole in rare minnow (Gobiocypris rarus) in a sex-dependent manner. Chemosphere 112, 154-162.

Liu, Y.-W., Lo, L.-J., Chan, W.-K., 2000. Temporal expression and T3 induction of thyroid hormone receptors $\alpha 1$ and $\beta 1$ during early embryonic and larval development in zebrafish, Danio rerio. Mol. Cell. Endocrinol. 159, 187-195.

Maddigapu, P.R., Minella, M., Vione, D., Maurino, V., Minero, C., 2010. Modeling phototransformation reactions in surface water bodies: 2 , 4-dichloro-6-nitrophenol as a case study. Environ. Sci. Technol. 45, 209-214.

Marchesini, G.R., Meulenberg, E., Haasnoot, W., Mizuguchi, M., Irth, H., 2006. Biosensor recognition of thyroid-disrupting chemicals using transport proteins. Anal. Chem. 78, 1107-1114.

Marchesini, G.R., Meimaridou, A., Haasnoot, W., Meulenberg, E., Albertus, F., Mizuguchi, M., Takeuchi, M., Irth, H., Murk, A.J., 2008. Biosensor discovery of thyroxine transport disrupting chemicals. Toxicol. Appl. Pharmacol. 232, $150-160$.

Martin, L., Klaassen, C.D., 2010. Differential effects of polychlorinated biphenyl congeners on serum thyroid hormone levels in rats. Toxicol. Sci. 117, 36-44.

Miller, M.D., Crofton, K.M., Rice, D.C., Zoeller, R.T., 2009. Thyroid-disrupting chemicals: interpreting upstream biomarkers of adverse outcomes. Environ. Health Perspect. 117, 1033-1041.

Morgado, I., Hamers, T., Van der Ven, L., Power, D.M., 2007. Disruption of thyroid hormone binding to sea bream recombinant transthyretin by ioxinyl and polybrominated diphenyl ethers. Chemosphere 69, 155-163.

Patrick, L., 2009. Thyroid disruption: mechanisms and clinical implications in human health. Altern. Med. Rev. 14, 326-347.

Porazzi, P., Calebiro, D., Benato, F., Tiso, N., Persani, L., 2009. Thyroid gland development and function in the zebrafish model. Mol. Cell. Endocrinol. 312, 14-23.

Raldúa, D., Babin, P.J., 2009. Simple, rapid zebrafish larva bioassay for assessing the potential of chemical pollutants and drugs to disrupt thyroid gland function. Environ. Sci. Technol. 43, 6844-6850.

Raldua, D., Thienpont, B., Babin, P.J., 2012. Zebrafish eleutheroembryos as an alternative system for screening chemicals disrupting the mammalian thyroid gland morphogenesis and function. Reprod. Toxicol. 33, 188-197.

Richardson, V.M., Staskal, D.F., Ross, D.G., Diliberto, J.J., DeVito, M.J., Birnbaum, L.S., 2008. Possible mechanisms of thyroid hormone disruption in mice by BDE 47 , a major polybrominated diphenyl ether congener. Toxicol. Appl. Pharmacol. 226, 244-250.

Schnitzler, J.G., Celis, N., Klaren, P.H., Blust, R., Dirtu, A.C., Covaci, A., Das, K., 2011. Thyroid dysfunction in sea bass (Dicentrarchus labrax): underlying mechanisms and effects of polychlorinated biphenyls on thyroid hormone physiology and metabolism. Aquat. Toxicol. 105, 438-447.

Schnitzler, J.G., Klaren, P.H., Bouquegneau, J.M., Das, K., 2012. Environmental factors affecting thyroid function of wild sea bass (Dicentrarchus labrax) from European coasts. Chemosphere 87, 1009-1017.

Shi, X., Du, Y., Lam, P.K., Wu, R.S., Zhou, B., 2008. Developmental toxicity and alteration of gene expression in zebrafish embryos exposed to PFOS. Toxicol. Appl. Pharmacol. 230, 23-32.

Shi, X., Liu, C., Wu, G., Zhou, B., 2009. Waterborne exposure to PFOS causes disruption of the hypothalamus-pituitary-thyroid axis in zebrafish larvae. Chemosphere 77, 1010-1018.

Sugiyama, S.-I., Shimada, N., Miyoshi, H., Yamauchi, K., 2005. Detection of thyroid system disrupting chemicals using in vitro and in vivo acreening assays in xenopus laevis. Toxicol. Sci. 88, 367-374.

Szabo, D.T., Richardson, V.M., Ross, D.G., Diliberto, J.J., Kodavanti, P.R., Birnbaum, L.S., 2008. Effects of perinatal PBDE exposure on hepatic phase I, phase II, phase III, and deiodinase 1 gene expression involved in thyroid hormone metabolism in male rat pups. Toxicol. Sci. 107 (1), 27-39.

Tognazzi, A., Dattilo, A.M., Bracchini, L., Rossi, C., Vione, D., 2012. Chemical characterisation of a new estuarine pollutant (2,4-dichloro-6-nitrophenol) and assessment of the acute toxicity of its quinoid form for Artemia salina. Int. J. Environ. Anal. Chem. 92, 1679-1688.

Vione, D., Maurino, V., Minero, C., Pelizzetti, E., Harrison, M.A., Olariu, R.-I., Arsene C., 2006. Photochemical reactions in the tropospheric aqueous phase and on particulate matter. Chem. Soc. Rev. 35, 441-453.

Vione, D., Minero, C., Housari, F., Chiron, S., 2007. Photoinduced transformation processes of 2,4-dichlorophenol and 2,6-dichlorophenol on nitrate irradiation. Chemosphere 69, 1548-1554.

Walpita, C.N., Van der Geyten, S., Rurangwa, E., Darras, V.M., 2007. The effect of 3,5,3'-triiodothyronine supplementation on zebrafish (Danio rerio) embryonic development and expression of iodothyronine deiodinases and thyroid hormone receptors. Gen. Comp. Endocrinol. 152, 206-214.

Walpita, C.N., Crawford, A.D., Janssens, E.D., Van der Geyten, S., Darras, V.M., 2009 Type 2 iodothyronine deiodinase is essential for thyroid hormone-dependent 
embryonic development and pigmentation in zebrafish. Endocrinology 150, 530-539.

Wang, Q., Liang, K., Liu, J., Yang, L., Guo, Y., Liu, C., Zhou, B., 2013. Exposure of zebrafish embryos/larvae to TDCPP alters concentrations of thyroid hormones and transcriptions of genes involved in the hypothalamic-pituitary-thyroid axis. Aquat. Toxicol. 126, 207-213.

Wang, Y., Zhou, J., Liu, L., Huang, C., Zhou, D., Fu, L., 2016. Characterization and toxicology evaluation of chitosan nanoparticles on the embryonic development of zebrafish, Danio rerio. Carbohydr. Polym. 141, 204-210.

Yang, X., Xie, J., Wu, T., Yue, G., Chen, J., Zhao, R., 2007. Hepatic and muscle expression of thyroid hormone receptors in association with body and muscle growth in large yellow croaker, Pseudosciaena crocea (Richardson). Gen. Comp. Endocrinol. 151, 163-171.

Yu, L., Deng, J., Shi, X., Liu, C., Yu, K., Zhou, B., 2010. Exposure to DE-71 alters thyroid hormone levels and gene transcription in the hypothalamic-pituitary-thyroid axis of zebrafish larvae. Aquat. Toxicol. 97, 226-233.
Yuan, L., Li, J., Zha, J., Wang, Z., 2016. Targeting neurotrophic factors and their receptors, but not cholinesterase or neurotransmitter, in the neurotoxicity of TDCPP in Chinese rare minnow adults (Gobiocypris rarus). Environ. Pollut. 208, 670-677.

Yue, M.S., Peterson, R.E., Heideman, W., 2015. Dioxin inhibition of swim bladder development in zebrafish: is it secondary to heart failure? Aquat. Toxicol. 162, $10-17$.

Zhu, B., Gong, Y.-X., Liu, L., Li, D.L., Wang, Y., Ling, F., Wang, G.-X., 2014. Toxic effects of triazophos on rare minnow (Gobiocypris rarus) embryos and larvae. Chemosphere 108, 46-54.

Zoeller, R.T., Tan, S.W., 2007. Implications of research on assays to characterize thyroid toxicants. Crit. Rev. Toxicol. 37, 195-210. 